\title{
EXAMINATION OF SHREDDING PROCESS PARAMETERS AND THE PROPERTIES OF RECYCLATE
}

\author{
Karolina Głogowska', Jakub Rozpędowski ${ }^{1}$ \\ 1 Department of Polymer Processing, Lublin University of Technology, Nadbystrzycka Str. 36, 20-618 Lublin, \\ Poland, e-mail: k.glogowska@pollub.pl
}

Received: 2015.12.15

Accepted: 2016.02.01

Published: 2016.03.01

\begin{abstract}
Shredding is the component of the most important techniques of mechanical recycling of polymeric materials. It is often used as one of the main preparatory processes, associated with the constitution of composite materials. This means that it is a very important and current problem to be solved in terms of technology, design, and economy, as well as environmental protection. A preparation of composite material components by shredding depends specfically on the expected degree of fineness, appropriate size distribution and desired morphology of an elementary particle. The subject of this work concerns mechanical shredding of polymeric materials in various types of mills and agglomerators. The paper presents the tests for verifying the influence of size and shapes of openings in sieves made in the shredder on selected parameters and properties of the obtained recyclate. During the shredding process, the following parameters were analysed: electricity consumption, temperature inside the shredding chamber and the temperature of the obtained recyclate. Selected properties of the obtained recyclate, such as: geometric features of the recyclate dependent on the applied sieves, bulk density and the angle of natural repose were also determined. Mouldings with a gating system, made of polypropylene, were the subject of shredding.
\end{abstract}

Keywords: injection moulding, polypropylene, shredding, recyclate.

\section{INTRODUCTION}

The use of shredders in industry is still increasing because of increasing possibilities of using recycled materials in manufacturing $[1,2]$. The aim of shredding is to obtain elements of a much smaller size than the shredded items. It is very import ant to choose an appropriate shredding method, because each material has a different susceptibility to shredding, depending on the mechanism involved $[3,4,5]$. The basic characteristics of the material, which determine the choice of shredding method, are the following: structure of the material, hardness, moisture content, particle size of the raw material, plasticity, etc. Technologies of the shredding process, its devices and parameters are adjusted to the type of waste [6]. Thanks to modern technological solutions, waste can be shredded to finer fraction comparable to the granules, and therefore can be used as a finished product for secondary processing [1].

The aim of our study was to determine the parameters for the shredding process, such as power consumption, temperature inside the shredding chamber and temperature of the obtained recyclate, as well as the determination of the recyclate properties: bulk density and the angle of natural repose determined with a variable shape and area of the openings of sieves in the cutter shredder.

\section{MATERIALS AND METHOD}

Test samples were made of polypropylene with a trade name Malen P S-901, manufactured by Lyondell Basell, shaped as samples without a notch to determine Charppy impact strength and 
with a filler system. This material is an isotactic homopolymer, intended primarily for injection, especially for the production of thin-walled articles with complex and long path of flow in the mould. The tested material was characterized with parameters presented in Table 1.

A screw injection molding machine Allrounder 320 C 500-170 from the company Arburg (Figure1a) was used to obtain samples. Moldings with the filler system were subjected to shredding.

The shredding process was conducted with the use of Rapid 2a cutter shredder (Figure 1b). In order to test the parameters of the shredding process, four sieves with dimensions of $240 \mathrm{~mm}$ to $80 \mathrm{~mm}$ and the surface area of $19200 \mathrm{~mm}^{2}$ were designed and made, varying in the size, shape and number of openings made in them (Table 2).

The first part of the study concerns the parameters of the shredding process; the tests were carried out consecutively for each type of sieve. 25 samples of a total mass of $500 \mathrm{~g}$ were the subject of shredding for each type of sieve, fed into the hopper of the shredder at an interval of 10 seconds. Each time before starting the shredding device, the sieves were mounted, the knives' position to each other was carefully adjusted, and the accuracy of mounting the upper part of the body was checked.
In order to accurately measure the power consumption, the shredded was connected in series to the power supply using a power meter. Bulk density measurement was conducted in accordance with the ISO 60:2011 standard. The study of the angle of natural repose of recyclate was conducted in accordance with the ISO 9276-1:2001 standard.

\section{RESULTS AND DISCUSSION}

Table 3 presents the results of energy consumption used for conducting the process, and the results of measuring the temperature inside the chamber during the process and the measurements of the recyclate is temperature.

On the basis of the obtained test results it was established that the size and shape of openings in the used sieves has a significant impact on power consumption. The consumption of electricity decrease along with increasing the size of sieves' openings and increasing their surface area. Reduced Power consumption in the sieves with larger openings is caused by a reduced energy requirement for shredding waste; the shredder cuts waste because it leaves the shredding chamber more quickly due to the size of openings, and the

Table 1. Basic properties of Malen P S-901

\begin{tabular}{|c|c|c|c|c|}
\hline Sieve No. & 1 & 2 & 3 & 4 \\
\hline Number of openings & 102 & 22 & 19 & 37 \\
\hline Shape of openings & circular & circular & rectangular & square \\
\hline Surface area of the sieve opening, $\mathrm{mm}^{2}$ & 28 & 113 & 378 & 225 \\
\hline Sum of the surface area of openings, $\mathrm{mm}^{2}$ & 2880 & 2496 & 5184 & 9408 \\
\hline Surface area of the sieve openings, \% & 15 & 13 & 27 & 49 \\
\hline
\end{tabular}
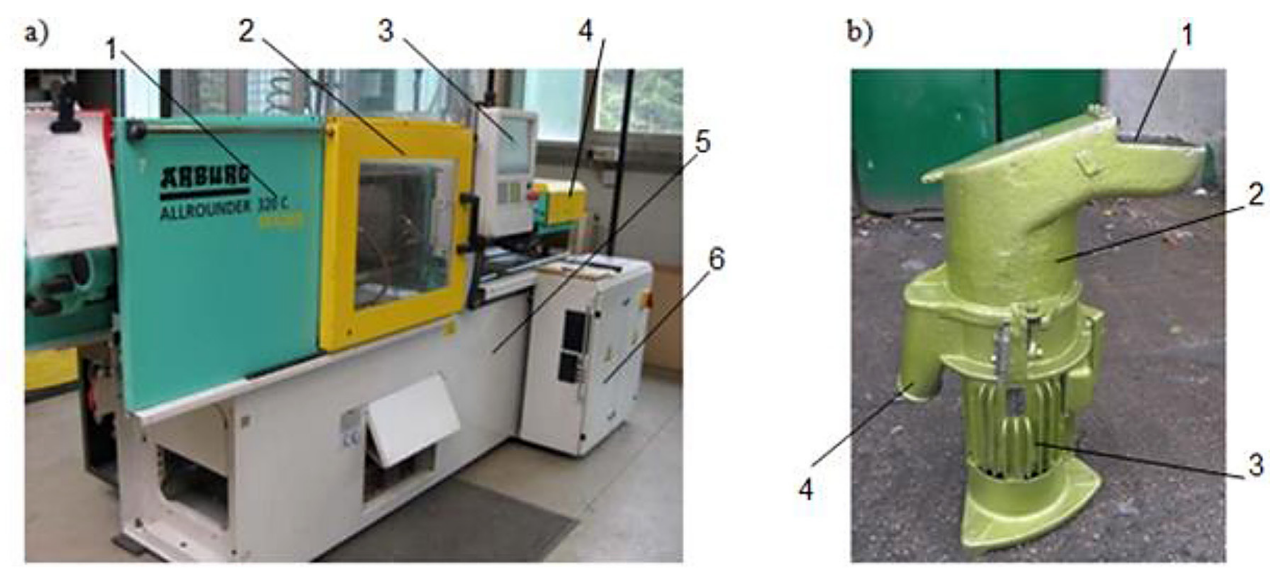

Fig. 1. a) Appearance of devices used for testing: Screw injection molding machine Allrounder 320 C 500-170 from the company Arburg: 1) cover, 2) closure unit, 3) control panel with flat screen and keyboard, 4) injection unit, 5) control cabinet, 6) body of the machine under the closure unit; b) Rapid 2a cutter shredded: 1) feeding hopper, 2) shredding chamber, 3) electric motor, 4) outlet channel 
Table 2. List of basic dimensions of sieves

\begin{tabular}{|l|c|}
\hline \multicolumn{1}{|c|}{ Properties } & Value \\
\hline Standard density $\left(23^{\circ} \mathrm{C}\right), \mathrm{kg} / \mathrm{m}^{3}$ & 920 \\
\hline Melt volume flow rate $\left(230^{\circ} \mathrm{C} ; 2.16 \mathrm{~kg}\right), \mathrm{cm}^{3} / 10 \mathrm{~min}$ & 7.6 \\
\hline Melt flow rate $\left(230^{\circ} \mathrm{C} / 2.16\right), \mathrm{g} / 10 \mathrm{~min}$ & 53 \\
\hline Maximum tensile stress, $\mathrm{MPa}$ & 30 \\
\hline Tensile strain at break, $\%$ & 50 \\
\hline Ball indentation hardness $(\mathrm{H} 358 / 30), \mathrm{MPa}$ & 80 \\
\hline
\end{tabular}

fraction obtained is composed of pieces of larger geometrical dimensions. An increase in the power consumption also occurs during the process, which is caused by collecting more and more unshredded pieces of material in the shredding material, which additionally burdens the device.

Analyzing the obtained measurement results it was found that an increase of temperature in the shredding chamber is influenced by the size of surface area of the sieve. A sieve with the area of openings of $15 \%$ in relation to the surface area of the whole sieve resulted in an increase of temperature by $2^{\circ} \mathrm{C}$, whereas a sieve with $49 \%$ of the openings area resulted in an increase by $0.8^{\circ} \mathrm{C}$. An increase of temperature is influenced by the number of cuts made by the shredder in order to shred waste at a predetermined size allowing for passage of pieces through the sieve open- ings. Moreover, the smaller area of openings, the more pieces in the form of waste contained in the shredding chamber, which causes an increase of temperature. Comparing the results of measuring temperature of recyclate, the same relation was observed as during the measurement of temperature of shredding chamber. It was also fund that the recyclate temperature increases along with the lengthening of the shredding time.

Figure $2 \mathrm{a}$ presents a summary of the results of studies of the natural angle of repose of the obtained recyclate. The results of measurement of the bulk density for each type of sieve are presented in Figure 2b.

On the basis of the obtained results of measurement of the natural angle of repose and the bulk density, it was established that the results are highly influenced by the size and shape of the tested recyclate. An increase in the studied values was observed, depending on the elements shredded with sieves with the opening of larger surface area.

\section{CONCLUSIONS}

The study shows that during the cuttingshredding process conducted with the shredder

Table 3. List of the results of measurement of power consumption, temperature inside the shredding chamber and the temperature of recyclate

\begin{tabular}{|c|c|c|c|c|c|c|}
\hline \multirow{2}{*}{$\begin{array}{c}\text { Sieve } \\
\text { No. }\end{array}$} & \multirow{2}{*}{$\begin{array}{c}\text { The amount of power } \\
\text { consumption }[\mathrm{kWh}]\end{array}$} & \multirow{2}{*}{$\begin{array}{c}\text { Temp. of the chamber } \\
\text { before the process }\left[{ }^{\circ} \mathrm{C}\right]\end{array}$} & $\begin{array}{c}\text { Temp. of the chamber } \\
\text { after the process }\left[{ }^{\circ} \mathrm{C}\right]\end{array}$ & \multicolumn{3}{|c|}{$\begin{array}{c}\text { Temperature of the recyclate }\left[{ }^{\circ} \mathrm{C}\right] \\
\text { and the time of measurement }[\mathrm{s}]\end{array}$} \\
\cline { 5 - 8 } & & & 90 & 180 & 250 \\
\hline 1 & 0.0238 & & 23.0 & 23.0 & 23.4 & 24.0 \\
\hline 2 & 0.0170 & \multirow{2}{*}{21} & 22.3 & 22.3 & 22.8 & 23.1 \\
\hline 3 & 0.0158 & & 21.9 & 22.0 & 22.2 & 22.4 \\
\cline { 5 - 8 } & & & 21.8 & 21.6 & 21.7 & 21.9 \\
\hline 4
\end{tabular}

a)

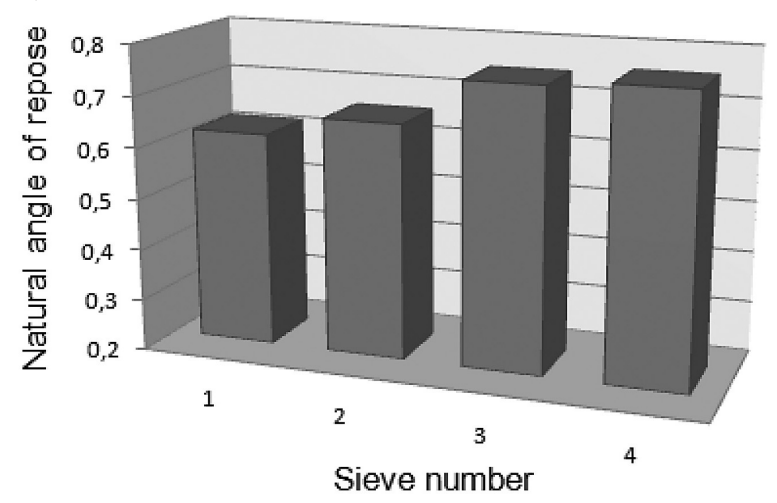

b)

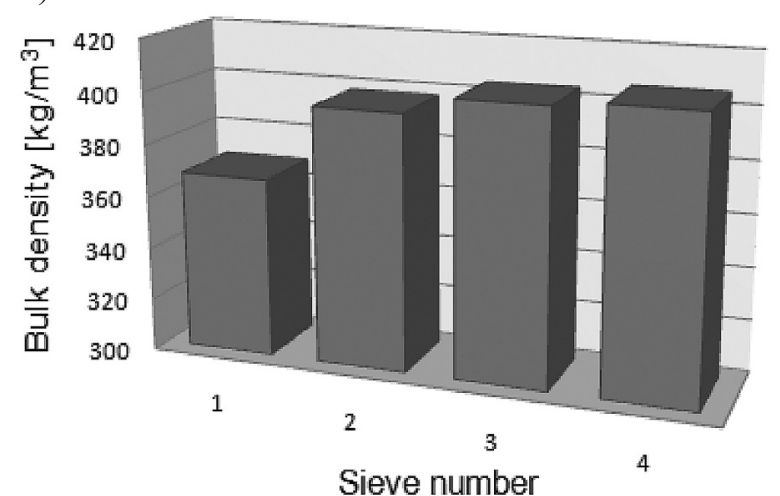

Fig. 2. Summary of tests: a) natural angle of repose of the recyclate for each type of sieve; b) bulk density of the obtained recyclate for each type of sieve 
Rapid 2a, the parameters of this process are significantly influenced by the shape, size and area of openings in the mounted sieves. There was an increase in power consumption and in temperature of the shredding chamber and the obtained recyclate when a sieve with the smallest area of openings was used for shredding. This was due to collecting material pieces in the shredding chamber, which had not reached the dimensions allowing for passage through the sieve openings. While comparing the obtained recyclate it was established that an increase of the size of sieve openings is accompanied by a decrease in the amount of dusty fraction. No significant influence of the shape of sieve openings on the parameters of the process was observed. It was concluded, from the measurement of the bulk density and the angle of natural repose, that its increase occurs by increasing the surface area of openings and changing their shape in the sieves.

The study indicates the importance of the possibility to shape the workspace of the shredder and the energy relations of the process. When choosing a shredder, one should choose such a construction variant that will guarantee the lowest energy expenditure, reasonable shredding performance and appropriate size and shape of the recyclate particles.

\section{REFERENCES}

1. Karlsson S. Recycled polyolefins, material properties and means for quality determination. Adv. Polym. Sci. 169, 2004, 201-230.

2. Scheirs J. Polymer recycling. Chichester, Wiley, New York 1998.

3. Goodship V. Introduction to plastic recycling Second edition. Smithers RApra Technology Limited, UK 2007.

4. Tall S. Recycling of mixed plastic waste - is separation worthwhile. Department of Polymer Technology, Royal Institute of Technology, SE100 44, Stockholm 2000.

5. Stefan T., Albertsson A.N., Karlsson S. Recycling of mixed plastic fractions: mechanical properties of multicomponent extruded polyolefin blends using response surfac methodology. Science J. Appl. Polym. Sci. 70(12), 1998, 2381-2392.

6. Garbacz T., Dulebova L., Krasinskyi V. Effectiveness of cellular injection molding process. Advances in Science and Technology Research Journal 7(18), 2013, 74-80. 